\title{
AXIAL TEMPERATURE AND PRESSURE
}

\author{
DISTRIBUTION IN EGCR.
}

\section{DEVELOPMENT OF THE PTD-1 PROGRAM}

\author{
James C. Robinson \\ James $T$. Lence
}

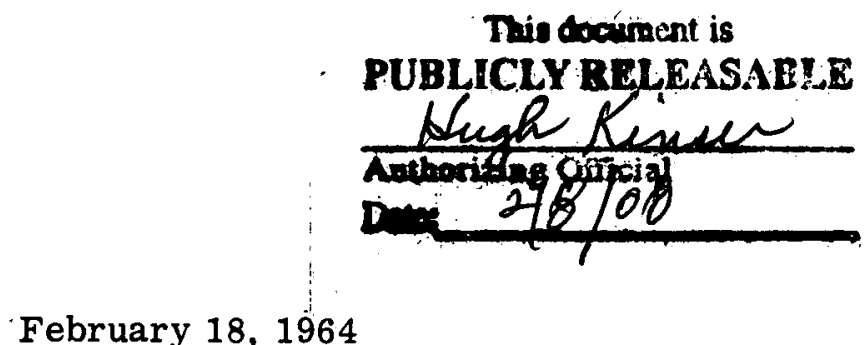

Experimental Gas-Cooled Reactor Operated By

The Tennessee Valley Authority at Oak Ridge 


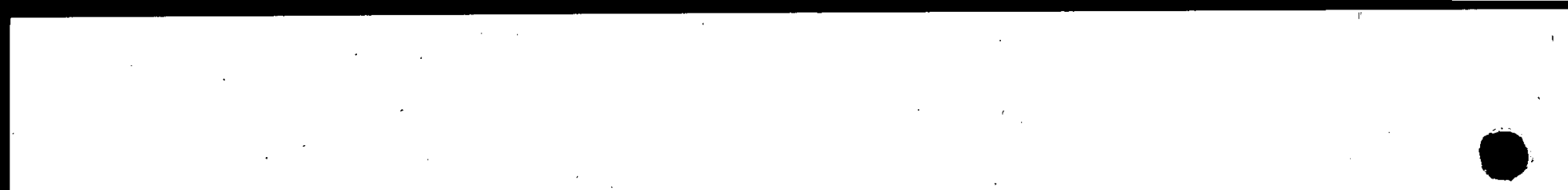

$?$

1

$\cdots$
$\cdots \cdots$

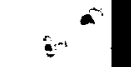

4

0 


\section{ABSTRACT}

Presented herein is the development of a program for the IBM 7090 for the purpose of obtaining the surface temperature distribution, the gas bulk temperature, and the pressure distribution for any of the 234 channels in the EGCR. The program is designed for any arbitrary power distribution yielding a constant gas outlet temperature or a given maximum surface temperature, and includes the effects of thermal radiation on surface and bulk gas temperatures. 


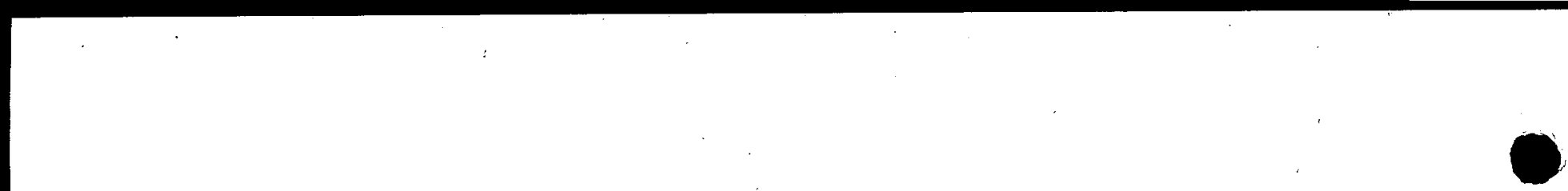




\section{ACKNOWLEDGMENT}

The author wishes to express his appreciation to D. Bagwell, G. E. Whitesides, and J. E. Rowe, all of Central Data Processing, Oak Ridge Gaseous Diffusion Plant, for advice and suggestions concerning programming these calculations. 


\section{AXIAL TEMPERATURE AND PRESSURE DISTRIBUTION IN EGCR}

\section{DEVELOPMENT OF THE PTD-1 PROGRAM}

\section{Introduction}

The Experimental Gas-Cooled Reactor is a gas-cooled power reactor being built at Oak Ridge, Tennessee, by the U. S. Atomic Energy Commission. The EGCR is operated by the Tennessee Valley Authority with fuel loading scheduled for 1965 .

The EGCR is fueled with enriched uranium dioxide clad in stainless steel, moderated with graphite, and cooled with helium. The helium coolant makes a single pass through the core, entering the bottom of the core at 313 psia and $510 \mathrm{~F}$, leaving the top at 303 psia and $1055 \mathrm{~F}$.

The core is built up of 16-inch by 16-inch graphite blocks, 19 feet 4 inches high. Each block has four 5.25-inch diameter vertical holes for the fuel channels. Fuel channels are on a square 8-inch pitch, and there is a total of 234 fuel channels (one channel may be filled with surveillance specimens). Each fuel channel contains six fuel assemblies and unfueled top and bottom dummies. Each fuel assembly (stacked height - 29 inches) contains a cluster of seven fuel elements (0.75-inch OD) which contains $\mathrm{UO}_{2}$ pellets inside 0.020 -inch stainless steel clad. The seven fuel elements are held in a graphite sleeve ( 5 inches OD by 3 inches ID) by a stainless steel top and bottom spider. Spacers are installed at the cluster axial midpoint to prevent bowing of the individual fuel elements. Figure 1 shows the EGCR fuel assembly. 


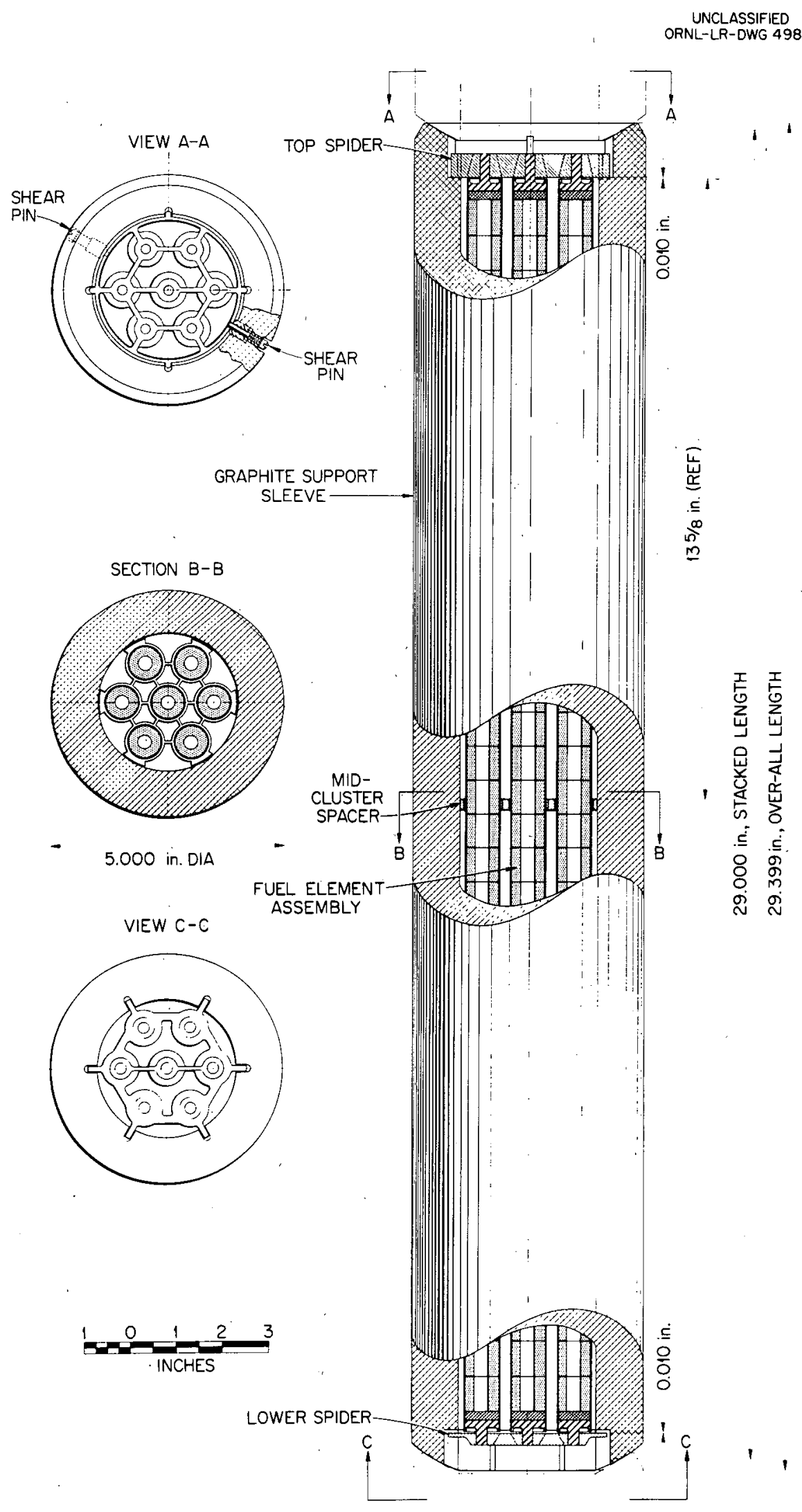

Fig. I

EGCR FUEL ASSEMBLY 
Each fuel channel is essentially a unit cell which may be considered to be an 8-inch square graphite block with a 5.25-inch diameter hole in the center for the fuel assemblies. The graphite sleeve of the fuel assembly has an outside diameter of 5 inches, leaving a $1 / 8$-inch annulus between the fuel assembly and the graphite block. Helium flows through this $1 / 8$-inch annulus parallel to the main fuel channel flow. This annulus flow removes gamma and neutron heat from the moderator block. The main coolant stream flows inside the graphite sleeve over the spiders and midcluster spacers and past the fuel elements to remove fission energy.

The bottom dummy has an orifice with an adjustable area so that flow to individual channels can be varied to give the desired fuel channel exit gas temperature. After passing through the variablearea orifice, part of the flow is diverted from the fuel elements to the annulus between fuel assembly and moderator block by means of orifices through the wall of the bottom dummy. Figure 2 is a schematic of the EGCR bottom dummy.

\section{Statement of the Problem}

The objective of this study is to write a Fortran program for the IBM 7090 digital computer which calculates the steady-state surface temperatures of the fuel clad, the graphite sleeve on both the fuel and annulus side, the moderator surface at the annulus, and the bulk temperature of the fuel cololant and annulus coolant. It is also desired to know the pressure drop from the exit of the bottom dummy to the top plenum and the required flow rate for a given operating program, thereby determining, assuming the characteristics of the orifice are known, 


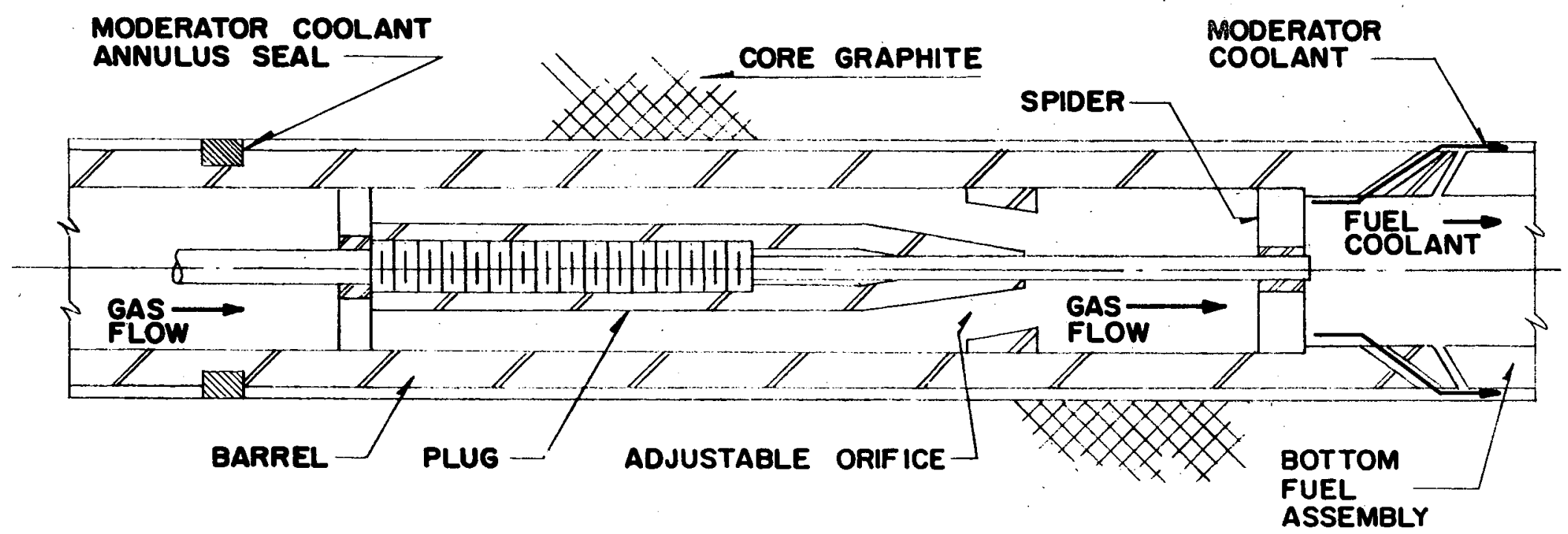

Fig. 2

SCHEMATIC OF CORE BOTTOM DUMMY 
where the bottom orifice must be set. The capability of considering thermal radiation between surfaces is considered desirable. The flexibility of examining any one of the 234 channels for any given power distribution and of examining the effects of radiation-induced reductions in graphite thermal conductivity, as well as the flexibility of calculating necessary flow rates to obtain either a specified channel exit gas temperature or a specified maximum fuel element surface temperature, is also considered desirable.

It is postulated at the beginning that the differential equations which might arise may be expressed as a series of finite difference-type equations, and then solved by a "marching ahead" type of solution. The pressure in the top plenum is the same for every channel; therefore, the "marching ahead" calculation for the pressure distribution must start in the top plenum and advance upstream to the bottom dummy. The temperature calculation must begin at the core inlet. From the mechanical energy balance, this requires that the friction factor, loss coefficients, and the bulk gas temperature distribution be known. The friction factor and the loss coefficients are obtained from work performed by ORNL (reference 7).

III. Thermal Analysis

The calculation of the gas temperature in this analysis requires knowledge of the amount of energy removed by the fuel channel coolant. Since about 6 percent of the reactor heat is generated in the sleeve and moderator block, it is deemed necessary to include them, along with the fuel elements and fuel coolant stream, in the analysis. 
1. This requires that a unit cell consisting of the fuel, sleeve, moderator, and coolant associated with one channel and extending the entire length of the core be isolated for analysis. This analysis yields the clad, sleeve, and block axial surface temperature distribution, along with the axial bulk gas temperature distribution.

This analysis requires knowlege of the various film coefficients, the power distribution, the amount of energy generated in the block, and the magnitude and distribution of the energy generated (axial and radial) in the sleeve.

The EGCR power distribution varies with time and with particular configuration of fuels and absorbers in the core. Thus, both the axial power distribution and the radial power distribution are input for the program and can be changed readily. For examples and reference purposes, the axial power distribution calculated in reference 8 is included as figure 3 .

It is assumed that the axial power distribution in the fuel may be applied to the sleeve and graphite block for each unit cell. While this assumption appears to be valid, it is not necessary to the solution of the problem. Different axial distributions for the fuel, sleeve, and graphite block could be used without severely complicating the solution.

It is assumed that the heat generation rate and heat transfer coefficient are uniform throughout the fuel cluster at any axial point. It is recognized that asymmetries exist around the fuel elements. Some asymmetries may be predicted and their effects on the fine temperature 
structure in the fuel cluster at a particular axial location may be estimated. Some asymmetries are unpredictable and the hot spot factors make allowances for their effects on the fine temperature structure at a particular axial location.

For the sake of simplicity, it is assumed that the heat generation rate in the graphite sleeve and block of each unit cell is dependent upon the fission energy released in only that unit cell. In other words, in calculating block and sleeve temperatures, it is assumed that radial thermal conduction from adjacent cells is negligible-i.e., thermal isolation--and that heat generation in one cell from nuclear radiation born in adjacent cells is negligible--i.e., nuclear isolation.

The assumption regarding thermal isolation of the unit cell appears to be valid when one considers that: (1) Each cell is insulated on two sides from adjacent cells by a helium gap, (2) temperature gradients in the blocks are found to be small, and (3) differences in power levels between adjacent cells are nọrmally also small.

The assumption regarding nuclear isolation is examined in some detail. Reference 5 gives values for the heat deposited in the sleeve and moderator of, all unit cells (each consisting of one fuel channel with associated fuel, sleeve, modérator, and coolant extending the length of the core) by gammas and fast neutrons normalized to one. Reference 5 also gives values for the thermal neutron flux in all unit cells normalized to one. Representative values are shown in tables 1 and 2 . If the fast neutron and gamma heat is divided by a number proportional to thermal neutron flux for each unit cell, and an approximate 
constant is obtained for all channels, then the assumption of nuclear isolation is valid. The last column in tables 1 and 2 shows that this is nearly a constant value. Therefore, to obtain the local radial sleeve and block heat generation rates, it is necessary only to multiply the constants found in tables 1 and 2 (which are only radial averages) by the ratio of the local-to-average radial power level. These local radial sources are corrected by the axial power distribution to obtain the appropriate heat generation rate for the sleeve or moderator at any unit cell radial and axial position. The heat generation rate in the fuel is obtained in similar fashion; therefore, any unit cell in the core for which analysis is desired is selected simply by putting the ratio of the local-to-average power at that position into the input of the code.

To obtain a coupling equation between the inner and outer surface temperatures of the sleeve, the steady-state thermal diffusion equation with source term is solved assuming radial diffusion only. The source in the sleeve is assumed to have a power law distribution in the radial direction, and the appropriate constants are determined by plotting heat generation rates from reference 5 as a function of position in the sleeve. The radial distribution used is:

$$
\frac{Q_{S}(r)}{Q_{\text {avg }}}=a r^{b}
$$

where

$$
\begin{aligned}
Q_{S}= & \text { heat generation in sleeve } \\
Q_{\text {avg }}= & \text { sleeve heat generation averaged over a radial section of } \\
& \text { the sleeve volume at any axial point }
\end{aligned}
$$


$r \quad=$ radial distance from center of cluster

a $=0.37$ (when $r$ is measured in feet)

$\mathrm{b}=-0.57$ (when $r$ is measured in feet)

A. Thermal Equations--At this point it is appropriate to present the equations which are solved by the computer. A general macroscopic thermal energy balance on the fluid, reference 1 , includes a change in potential and kinetic energy, but both of these terms are neglected in this analysis. These terms can be shown to be small. Further, if both of these terms are carried through, the calculations are lengthened tremendously. This can be verified by recalling that a "marching ahead" type of solution is used, and the inlet temperature and exit pressure are the starting points. The change in kinetic energy couples pressure and temperature through the equation of conservation of mass and the equation of state; therefore, if this term is included, an iterative type of solution is required.

Neglecting the kinetic and potential energy terms, the steadystate energy balance becomes

\begin{tabular}{|c|c|c|c|c|}
\hline $\begin{array}{l}\text { Change } \\
\text { in } \\
\text { Enthalpy }\end{array}$ & $=$ & $\begin{array}{l}\text { Net Thermal Energy } \\
\text { in } \\
\text { Due to Friction }\end{array}$ & + & $\begin{array}{l}\text { Net Thermal Energy } \\
\text { in } \\
\text { Due to Convection }\end{array}$ \\
\hline
\end{tabular}




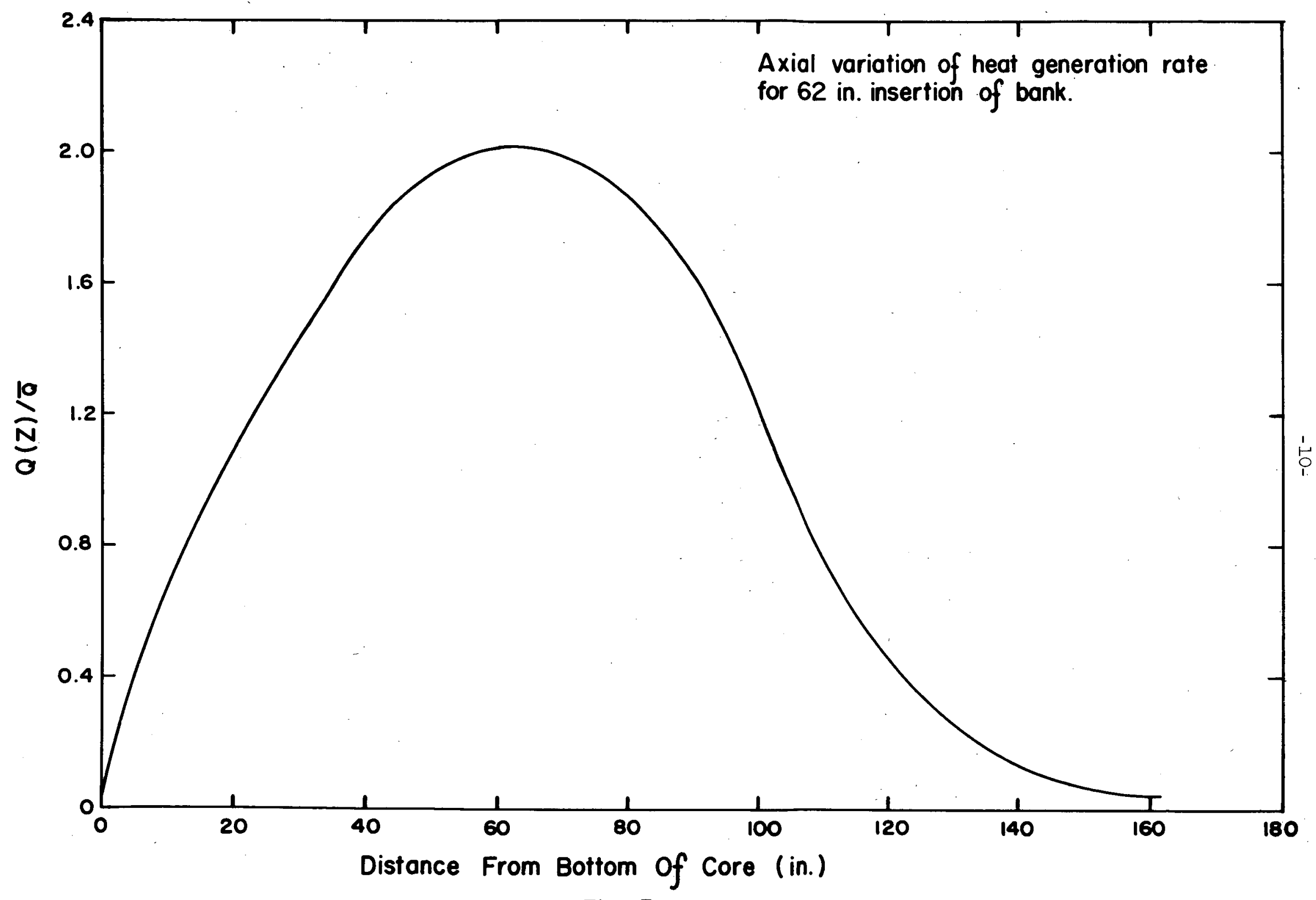

Fig. 3 
TABLE 1

NORMAIIZED SOURCE IN MODERATOR BLOCK

for

REPRESENTATIVE SECTIONS OF EGCR CORE

Channel No.*

$\frac{\phi}{\Phi_{\text {avg }}}$

$\mathrm{Q}_{\mathrm{B}}(\mathrm{kw})$

$\frac{Q_{B} \cdot \quad \operatorname{avg}(k w)}{\phi}$

126

0.946

16.993

17.963

127

1. .203

19.301

16.044

128

1.359

22.049

16.221

129

1.356

22.967

16.937

130

1.274

21.818

17.126

131

1.146

19.670

17.164

132

0.993

17.097

17.217

133

0.830

14.253

17.172

143

1. 359

22.044

16.221

234

1. 332

21.405

16.070

144

1. 342

21.954

16.359

1.45

1.278

21.695

16.976

146

1.165

$19.977^{*}$

17.148

147

1.026

17.644

17.197

148

0.878

15.069

17.163

149

0.779

$11.884^{\circ}$

15.255

The average of $Q_{B} \frac{\phi \text { avg }}{\phi}=16.76 \mathrm{kw}$

*For numbering system, see drawing No. 5927-EGCR-MS270 or figure 4.3.2.1 of reference 10 . 


\section{TABLE 2}

NORMALIZED SOURCE IN SLEEVE

for

REPRESENTATIVE SECTIONS OF EGCR CORE

Channel No.*

$$
\frac{\Phi}{\Phi \text { avg }}
$$

$Q_{S}(k w)$

$\frac{Q_{S} \Phi \text { avg }}{\phi}(\mathrm{kw})$

\begin{tabular}{|c|c|c|c|}
\hline 126 & 0.946 & 6.083 & 6.430 \\
\hline 127 & 1.203 & $7 \cdot 735$ & 6.430 \\
\hline 128 & 1.359 & 8.738 & 6.430 \\
\hline 129 & $1 \cdot 356$ & 8.719 & 6.430 \\
\hline 130 & 1.274 & 8.181 & 6.422 \\
\hline 131 & 1.146 & $7 \cdot 313$ & 6.381 \\
\hline 132 & 0.993 & 6.384 & 6.429 \\
\hline 133 & 0.830 & 5.292 & 6.376 \\
\hline 134 & 0.728 & 4.681 & 6.430 \\
\hline 143 & 1.359 & 8.738 & 6.430 \\
\hline 234 & 1.232 & 8.564 & 6.429 \\
\hline 144 & 1.342 & 8.629 & 6.430 \\
\hline 145 & 1.278 & 8.217 & 6.430 \\
\hline 146 & 1.165 & 7.491 & 6.430 \\
\hline 147 & 1.026 & 6.597 & 6.430 \\
\hline 148 & 0.878 & 5.646 & 6.430 \\
\hline 149 & 0.779 & 5.009 & 6.430 \\
\hline
\end{tabular}

The average of $Q_{\mathrm{S}} \frac{\phi \text { avg }}{\Phi}=6.423 \mathrm{kw}$

*For numbering system, see drawing No. 5927-EGCR-MS270 or figure 4.3.2.1 of reference 10 . 


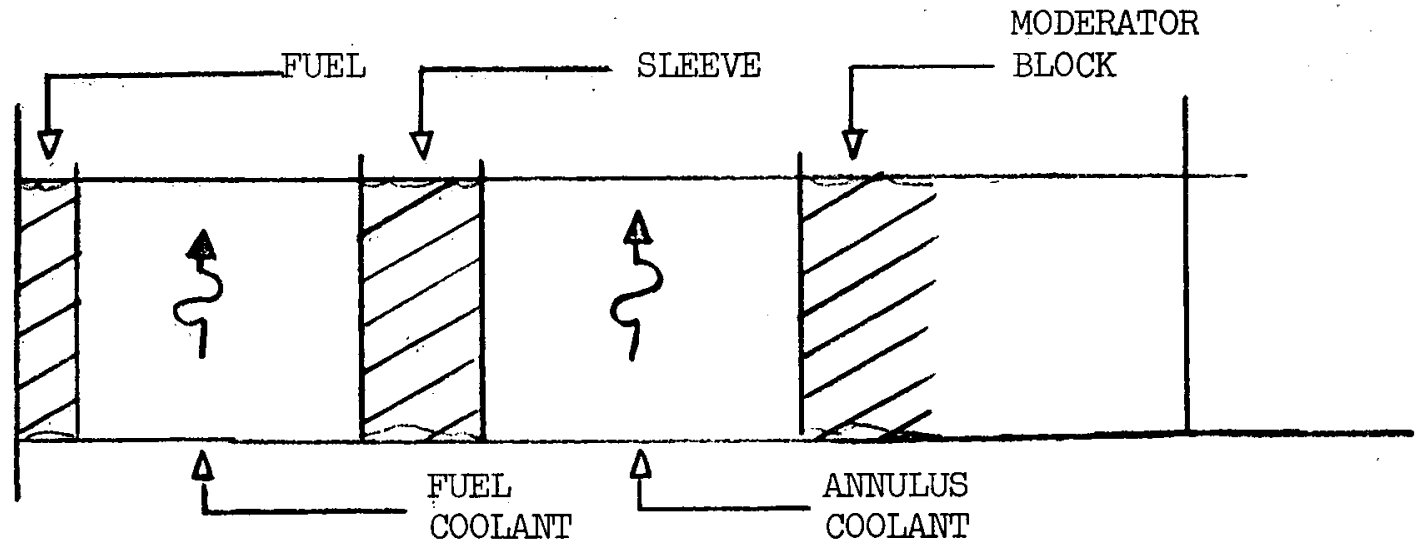

\section{Figure 4 - Sketch Illustrating the Basis for Obtaining the Working Equations}

Consider the sketch in figure 4 and assume (a) that the surface temperatures can be treated as constant over small axial increments, and there is no axial conduction; (b) that thermal energy is transported from (or to) the surfaces by convection and radiation; (c) that the heat transfer coefficients are known; and (d) that friction heating of annulus gas is negligible.

At steady-state conditions the energy balances are:

$\left[\begin{array}{l}\text { Heat generated in } \\ \text { fuel per unit length }\end{array}\right]=\left[\begin{array}{l}\text { heat transferred to fuel } \\ \text { coolant by convection }\end{array}\right]$

$$
+\left[\begin{array}{l}
\text { heat transferred to } \\
\text { sleeve by radiation }
\end{array}\right]
$$

or, in equation form,

$$
Q_{F}=P_{C} h_{C}(T C-T F)+P_{c} R_{c}(T C-T S F)
$$


$\left[\begin{array}{l}\text { Heat into unit mass of } \\ \text { fuel coolant per unit length }\end{array}\right]=[$ heating due to friction $]$

$+[$ heat transferred from fuel $]$

$+[$ heat transferred from sleeve $]$

or, in equation form,

$$
\begin{aligned}
\frac{g_{c}}{g} j C_{p} \frac{d(T F)}{d z} & =\frac{1}{2}\left(\frac{W F}{g^{0.5} A_{F} \rho}\right)^{2} \frac{4 f}{D_{e}} \\
& +\delta\left(z-z_{j}\right)\left(\frac{W F}{g^{0.5} A_{F} \rho}\right)^{2} e_{V} \\
& +\frac{g_{C} j}{g(W F)}\left\{P_{C} h_{C}(T C-T F)+P_{S f} h_{S f}(T S F-T F)\right\}
\end{aligned}
$$

$\left[\begin{array}{l}\text { Heat generated in } \\ \text { sleeve per unit length }\end{array}\right]=\left[\begin{array}{l}\text { heat transferred to } \\ \text { fuel coolant by convection }\end{array}\right]$

$$
\begin{aligned}
& +\left[\begin{array}{l}
\text { heat transferred to annulus } \\
\text { coolant by convection }
\end{array}\right] \\
& +\left[\begin{array}{l}
\text { heat transferred from sleeve to } \\
\text { moderator block by radiation }
\end{array}\right] \\
& -\left[\begin{array}{l}
\text { heat transferred from fuel } \\
\text { to sleeve by radiation }
\end{array}\right]
\end{aligned}
$$

or, in equation form,

$$
\begin{aligned}
Q_{S}= & P_{S f^{h}} h_{S f}(T S F-T F)+P_{S a} h_{s a}(T S A-T A)+R_{S} P_{S a}(T S A-T B)- \\
& R_{c} P_{c}(T C-T S F)
\end{aligned}
$$


$\left[\begin{array}{l}\text { Heat generated in the moderator } \\ \text { block per unit length }\end{array}\right]=\left[\begin{array}{l}\text { heat transferred to annulus } \\ \text { coolant by convection }\end{array}\right]$.

- $\quad\left[\begin{array}{l}\text { heat transferred from sleeve } \\ \text { to block by radiation }\end{array}\right]$

or, in equation form,

$Q_{B}=P_{B} h_{B}(T B-T A)-R_{S} P_{S a}(T S A-T B)$

$\left[\begin{array}{l}\text { Heat into annulus } \\ \text { coolant per unit length }\end{array}\right]=[$ heat transferred from sleeve $]$ $+[$ heat transferred from block $]$

or, in equation form,

$$
\text { (WA } C_{p} \frac{d(T A)}{d z}=P_{B} h_{B}(T B-T A)+P_{s a h} h_{s a}(T S A-T A)
$$

where

$P=$ perimeter and subscripts $c$, sf, sa, and $B$ refer to fuel clad, sleeve on fuel side, sleeve on annulus side, and the moderator block

$h=$ heat transfer coefficient and subşcripts $c$, sf, sa, and $B$ refer to fuel clad, sleeve on fuel side; sleeve on annulus side; and the moderator block

$Q=$ heat generation rate per unit axial length and the subscripts $F, s$, and $B$ refer to fuel, sleeve, and thè moderator block $\mathrm{TC}=$ absolute surface temperature of the fuel clad $\left({ }^{\circ} R\right)$ $\mathrm{TF}=$ absolute bulk gas temperature of the fuel coolant $\left({ }^{\circ} \mathrm{R}\right)$ TSF = absolute surface temperature of the sleeve on the fuel side $\left({ }^{\circ} \mathrm{R}\right)$ 
TSA = absolute surface temperature of the sleeve on the annulus side $\left({ }^{\circ} \mathrm{R}\right)$

$\mathrm{TA}=$ absolute bulk gas temperature of the annulus coolant $\left({ }^{\circ} \mathrm{R}\right)$

$\mathrm{TB}=$ absolute surface temperature of the block $\left({ }^{\circ} \mathrm{R}\right)$

$A_{F}=$ cross-sectional flow area for the fuel coolant passage

$W F=$ fuel flow rate

$W A=$ annulus flow rate

$\rho=$ gas density

$D_{e}=$ equivalent diameter

$z=$ axial distance measured from the bottom of the core

$\mathrm{e}_{\mathrm{v}}=$ loss coefficient at various interruptions

$f=$ fanning friction factor

$\delta\left(z-z_{j}\right)=$ Dirac-delta function (the function has zero values except at spacers and spiders)

$j=$ mechanical equivalent of heat

$g_{c}=$ dimensional constant

$g$ = gravitational acceleration

$R=$ effective radiative film coefficient, where subscript $c$ refers to clad to sleeve and s refers to sleeve to moderator block, defined by

$R_{C} P_{C}(T C-T S F)=P_{C} \mathcal{F}_{C}{ }_{S} \sigma \quad\left(T C^{4}-T S F^{4}\right)$

$\mathrm{R}_{\mathrm{S}} \mathrm{P}_{\mathrm{Sa}}(\mathrm{TSA}-\mathrm{TB})=\mathrm{P}_{\mathrm{Sa}} \mathcal{F}_{\mathrm{Sa}} \underset{\mathrm{B}}{\sigma}\left(\mathrm{TSA}^{4}-\mathrm{TB}^{4}\right)$

where the radiative view factor $\left(\mathcal{F}_{c \rightleftarrows s}\right)$ is taken from reference 2 . 
Thus far, we have five equations and six unknowns; therefore, a sixth equation is required. The sixth equation is obtained by integrating across the sleeve, using the source term from equation 1 . The result is

$$
\begin{gathered}
T S F-T S A=\frac{a Q_{a v g}}{k_{m}(b+2)^{2}}\left[\begin{array}{cr}
b+2 & b+2 \\
r_{2} & -r_{1}
\end{array}\right] \\
\quad \frac{r_{1}}{k_{m}} \ln \frac{r_{2}}{r_{1}}\left[R_{c}(T C-T S F)-h_{S f}(T S F-T F)\right]- \\
\quad \frac{1}{k_{m}} \ln \frac{r_{2}}{r_{1}}\left[\frac{a}{b+2} r_{1}^{b+2}\right] Q_{a v g}
\end{gathered}
$$

where

$r_{1}$ and $r_{2}$ are the inside and outside radii (in feet) respectively $a$ and $b$ are the coefficients for the source term in equation 1

$$
\begin{aligned}
& a=0.37 \\
& b=-0.57
\end{aligned}
$$

$Q_{\text {avg }}=$ sleeve heat generation averaged over an axial section of the sleeve volume

$k_{m}=$ the thermal conductivity (radial) of the graphite sleeve This completes six equations and six unknowns; hence the temperature distribution can be obtained:

B. Film Heat Transfer Coeffièients--As indicated earlier, it is assumed that the various film coefficients are known; however, it is appropriate at this point to discuss the film coefficients which are used at the various surfaces in the program. 
1. Fuel Cladding Coefficients

The film coefficient used for energy removed by convection from fuel clad is that given in reference 8, i.e.,

$$
\mathrm{h}_{\mathrm{C}}=\frac{\mathrm{C}_{\mathrm{L}}}{\mathrm{D}_{\mathrm{e}}} \mathrm{k}_{\mathrm{s}} \operatorname{Pr}_{\mathrm{s}} 0.4 \operatorname{Re}_{\mathrm{g}} 0.8 \frac{\mathrm{TF}}{\mathrm{TC}} \frac{\mu \mathrm{g}}{\mu_{\mathrm{s}}}
$$

where

$$
\begin{aligned}
\mathrm{C}_{\mathrm{L}}= & \text { modified Dittus-Boelter coefficient, reproduced in } \\
& \text { figure } 5 \\
\mathrm{k}= & \text { gas thermal conductivity where subscript s refers } \\
& \text { to the surface temperature and subscript } \mathrm{g} \text { refers } \\
& \text { to bulk gas temperature } \\
\operatorname{Pr}= & \text { gas Prandtl number where subscript s refers to } \\
& \text { surface temperature and subscript } \mathrm{g} \text { refers to gas } \\
& \text { temperature } \\
\mu= & \text { gas viscosity where subscript s refers to surface } \\
& \text { temperature and subscript } \mathrm{g} \text { refers to gas temperature } \\
\operatorname{Re}_{\mathrm{g}}= & \text { Reynolds number of gas at bulk gas conditions }
\end{aligned}
$$

From helium property data, reference 9 , the variation in

thermal conductivity and viscosity can be expressed as

$$
\begin{aligned}
& k=\left(9.375 \times 10^{-5}\right) \mathrm{T}+0.040 \\
& \mu=\left(5.25 \times 10^{-5}\right) \mathrm{T}+0.023
\end{aligned}
$$

where

$$
\begin{aligned}
& T \text { is in }{ }^{\circ} \mathrm{R} \\
& \mathrm{k} \text { is in Btu per hr per ft per }{ }^{\circ} \mathrm{R} \\
& \mu \text { is in } \mathrm{lb} \text { per ft per } h r
\end{aligned}
$$




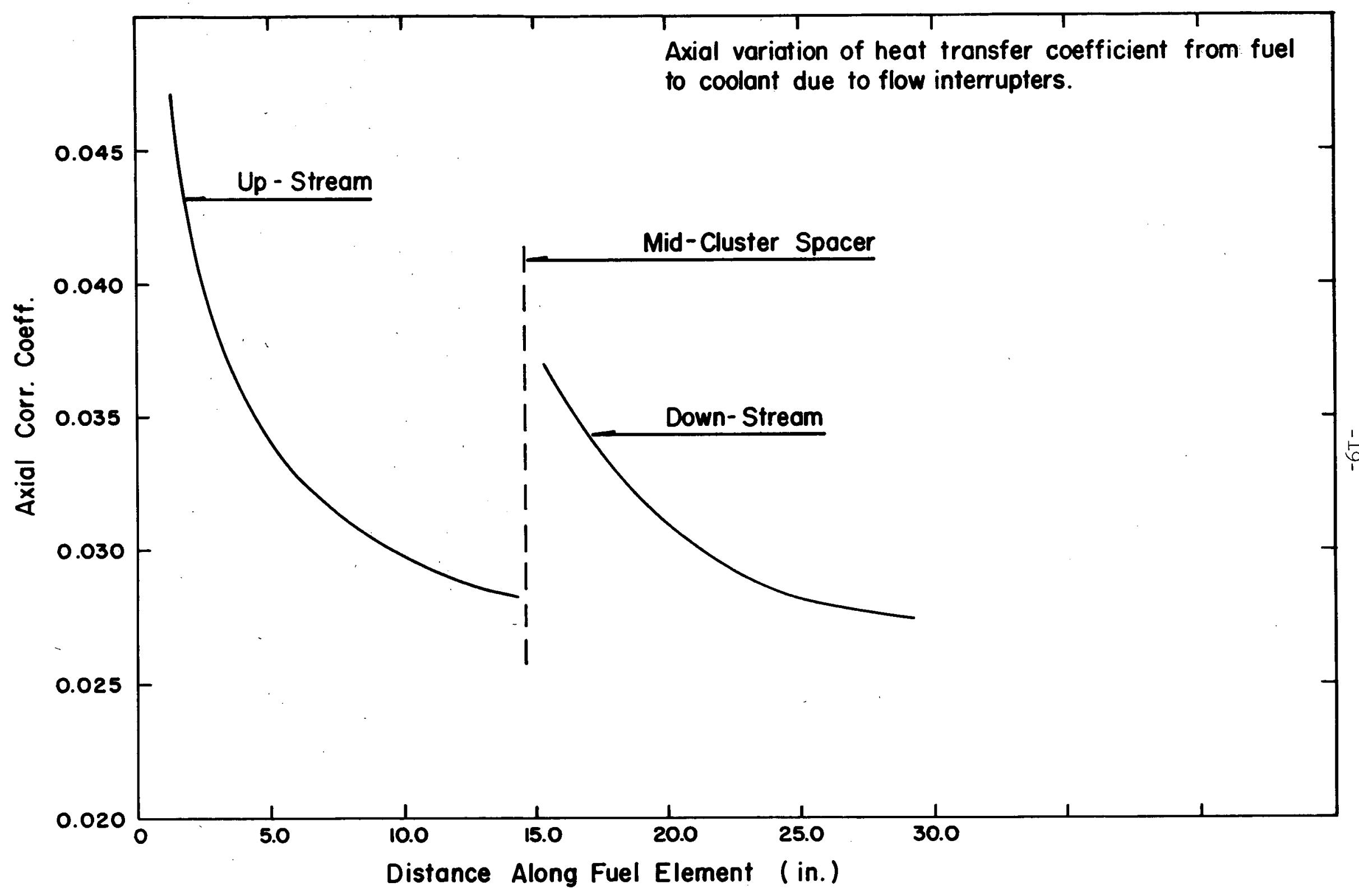

Fig. 5 
A check was made on the variation of $\left(\operatorname{Pr}_{S}\right)^{0.4}$ and $\mu_{g} 0.2$ with temperature, and it was found that the variation was small relative to a mean value; therefore, mear values are used and these quantities are treated as constants.

Thus, using equations 9 and 10 , equation 8 can be written as

$$
\begin{aligned}
\mathrm{n}_{\mathrm{C}}= & \frac{\mathrm{C}_{\mathrm{L}}}{\left(\mathrm{D}_{\mathrm{e}}\right) 0.2}\left(\frac{\mathrm{TF}}{\mathrm{TC}}\right) \operatorname{Pr}_{\mathrm{S}}{ }^{0.4} \frac{\mathrm{WF}^{0.8}}{\left(\mathrm{~A}_{\mathrm{F}}\right)^{0.8}} \mu_{\mathrm{g}}^{0.2} \\
& {\left[\frac{\left(9.375 \times 10^{-5}\right) \mathrm{TC}+0.040}{\left(5.25 \times 10^{-5}\right) \mathrm{TC}+0.023}\right] }
\end{aligned}
$$

Equation 11 is the expression used in the program for the film coefficient at the fuel surface.

\section{Sleeve Coefficient - Fuel Side}

Since equation 8 is in the Dittus-Boelter form, this equation is assumed to be valid for any section where turbulent flow prevails, but the coefficient $\left(C_{I}\right)$ is modified at the various surfaces. At the sleeve surface on the fuel coolant side, 0.023 is used; however, a correction is made due to axial position. It is reasoned that since the spacers, spiders, etc., had such a significant effect on the fuel clad coefficient (see figure 5), then a similar effect is felt at the sleeve surface. Since no experimental data is available to indicate the degree of this effect, it is assumed that the Dittus-Boelter equation is a lower limit for the heat transfer coefficient. The minimum value of the axial 
coefficient in figure 5 is normalized to a minimum value of unity, and then the variation above unity is reduced arbitrarily by 50 percent. This coefficient is given in figure 6. $\mathrm{C}_{\mathrm{I}}$ for equation 8 is obtained by multiplying 0.023 by the values taken from figure 6 .

3. Coefficients in the Annulus

The flow rate in the annulus is such that the Reynolds number, based on the equivalent diameter, implies that the flow is either laminar or in the transition region; therefore, the Dittus-Boelter equation is not applicable over the full range of flows expected. The laminar film coefficient could not be obtained by assuming an equivalent diameter as applied to pipe flow since the difference in laminar flow regime set up in a pipe and the flow regime in an annulus leads to appreciable error. The equation used for laminar flow in the annulus is that taken from reference 4 , and it is

$$
\begin{aligned}
& h_{B}=h_{s a}=1.02 \frac{k_{g}}{D_{e}}\left(R_{g}\right)^{0.45}\left(\operatorname{Prg}_{g}\right)^{0.5}\left(\frac{\mu_{g}}{\mu_{s}}\right)^{0.14} \\
& \left(\frac{D_{e}}{L}\right)^{0.4}\left(\frac{D_{2}}{D_{1}}\right)^{0.8}(G r)^{0.05}
\end{aligned}
$$

where

$D=$ diameter, subscript 1 refers to the sleeve diameter and subscript 2 refers to the block diameter

$\mathrm{Gr}=$ Grashof number based on $\mathrm{D}_{\mathrm{e}}$ and the temperature difference between inner surface and arithmetic mean gas temperature 


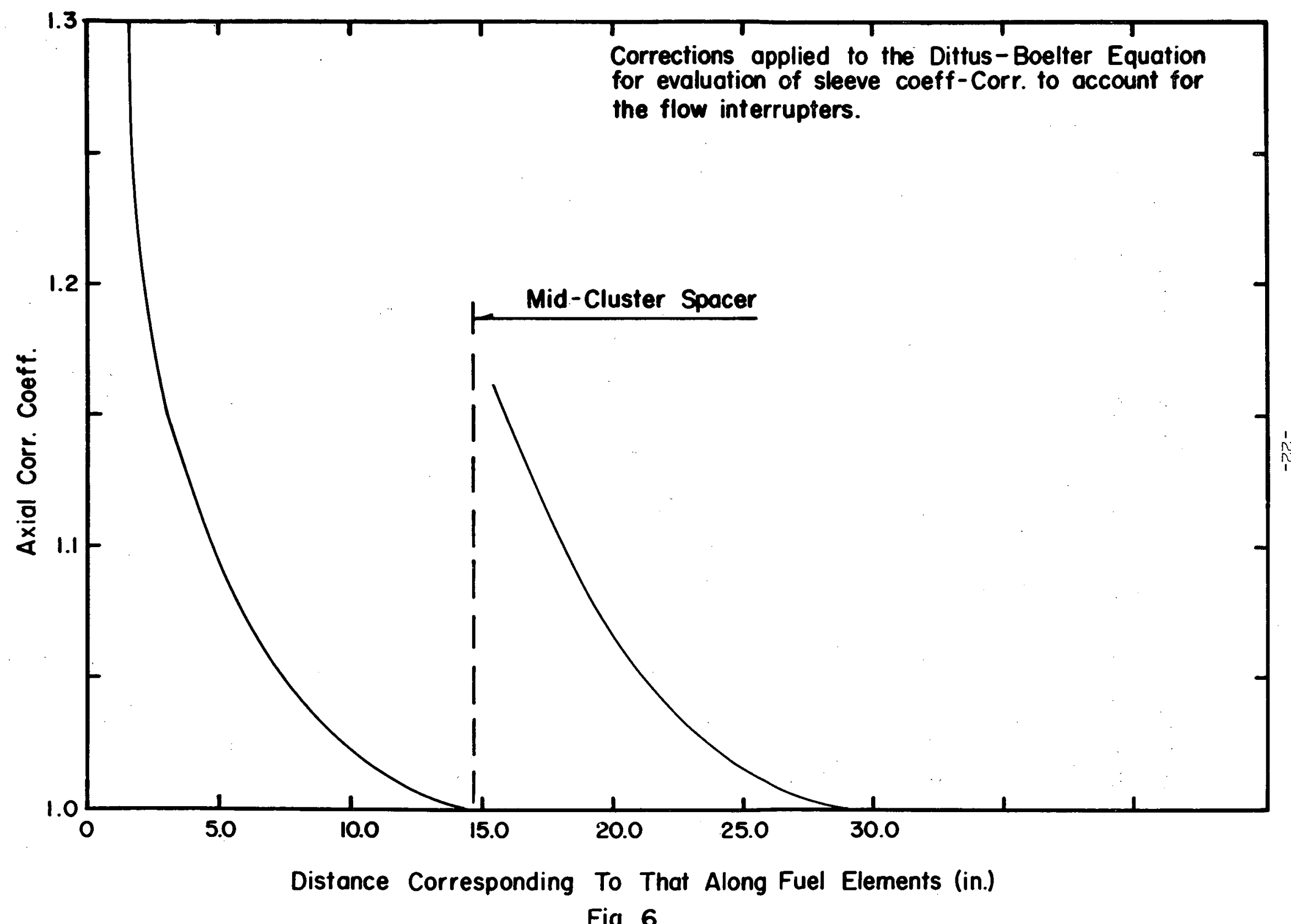

Fig. 6 
This equation is used for $R e \leq 2000$, and the Dittus-Boelter equation is used for $\operatorname{Re} \geq 6000$. A linear interpolation is used for $2000<\operatorname{Re}<6000$. Note that it is assumed that there is no cocking or misalignment in fuel assemblies (true annulus).

\section{Pressure Analysis}

Once the temperature distribution is obtained, it is possible to calculate the pressure distribution, using the friction data from ORNL. The equations used for the pressure distribution are mechanical energy balance (reference 1), equation of state (ideal gas), and conservation of mass (steady flow rate). The mechanical energy balance is

$$
\frac{v d v}{g_{c}}+\frac{d p}{\rho}+\frac{2 v^{2}}{D_{e} g_{c}} f d z+\delta\left(z-z_{j}\right) \frac{v^{2}}{2 g_{c}} e_{v} d z=0
$$

where

$$
\mathrm{v}=\text { average velocity }
$$

$$
\mathrm{vdv}=\text { change in } \mathrm{KE}
$$

By using the equation of state and the conservation of mass, equation 13 . is put into the form

$$
\begin{gathered}
-\frac{d p}{p}+\frac{d T}{T}+\frac{\left[A_{F} /(W F)\right]^{2} \cdot g_{c}}{\left(R_{0} / M\right) T} p d p+\frac{1}{2} \cdot \frac{4 f}{D_{e}} d z+ \\
\frac{\delta\left(z-z_{j}\right)}{2} e_{v} d z=0
\end{gathered}
$$

where

$$
R_{O}=\text { universal gas constant, } 1545.33 \mathrm{ft}-1 \mathrm{bf} / 1 \mathrm{bm}-\mathrm{mole}-{ }^{\circ} \mathrm{R}
$$


$\mathrm{M}=$ molecular weight, $\mathrm{lbm} / \mathrm{lbm}-\mathrm{mole}$

$\mathrm{TF}$ is replaced by $\mathrm{T}$ (bulk fluid temperature). In integrated form, equation 14 is

$$
\begin{aligned}
-\ln \frac{p_{2}}{p_{1}}+\ln \frac{T_{2}}{T_{1}}+\frac{\left[A_{F} /(W F)\right]^{2}}{\left(R_{0} / M\right)} g_{C} \frac{\bar{p}}{\frac{T}{T}}\left(p_{2}-p_{1}\right)+ \\
\quad \frac{4 f}{2 D_{e}}\left(z_{2}-z_{1}\right)+\frac{1}{2} \int_{z_{1}}^{z_{2}} \delta\left(z-z_{j}\right) e_{v} d z \approx 0
\end{aligned}
$$

where

$$
\int_{p_{1}}^{p_{2}} \frac{p}{T} d p \approx \frac{\bar{p}}{\frac{T}{T}} \Delta p
$$

with

$$
\bar{p}=\frac{1}{2}\left(p_{1}+p_{2}\right) \text { and } \bar{T}=\frac{1}{2}\left(T_{1}+T_{2}\right)
$$

and subscript 2 refers to mesh point $(i+1)$ subscript 1 refers to mesh point (i) with $z_{i+1}>z_{i}$.

The approximation in equation 15 implies that increments in axial position must be taken small enough so that negligible error is introduced by taking $\frac{p}{T}$ as a constant given by their respective average values. Equation 15 is the equation used to obtain the pressure distribution by the program.

\section{Development of the Program}

The unit cell is divided into 85 axial mesh points. Each of the six fuel assemblies has 14 mesh points; 13 of these mesh points represent a 2-inch fueled increment, the other mesh point represents 
the 3-inch unfueled section between fuel assemblies. There is one section preceding the first fuel assembly and one section above the last fuel assembly. The latter represents the top dummy. The mesh point spacing is shown in figure 7 and in table 3 .

It should be noted that the mesh points define the end points of the axial increments used in the calculation and that gas temperatures and pressures are calculated at the mesh points, but surface temperatures are calculated midway between mesh. points and are, therefore, displaced one-half an axial increment from the mesh points. Or, in order to calculate surface temperatures, gas temperatures are displaced one-ralf an axial increment from the mesh points at which the gas temperatures are calculated. For example, the gas temperatures at mesh point 3 are calculated from reactor inlet temperature and heat sources below mesh point 3. These gas temperatures are used to calculate surface temperature between mesh points 3 and 4 . Then new gas temperatures are calculated at mesh point 4; these new temperatures are used to calculate surface temperatures between mesh points 4 and 5 .

It should also be noted that pressure is not calculated at mesh point 87 because experimental values for the top dummy loss coefficient include the hanger spider from the top fuel element. Thus, the first pressure calculated is for mesh point 86.

The top and bottom plenum are each common to all channels. Reference 3 demonstrates that the pressure is uniform across each plenum; and that one can expect good mixing of the gas in the bottom plenum. For the purposes of developing the computer program, it is 

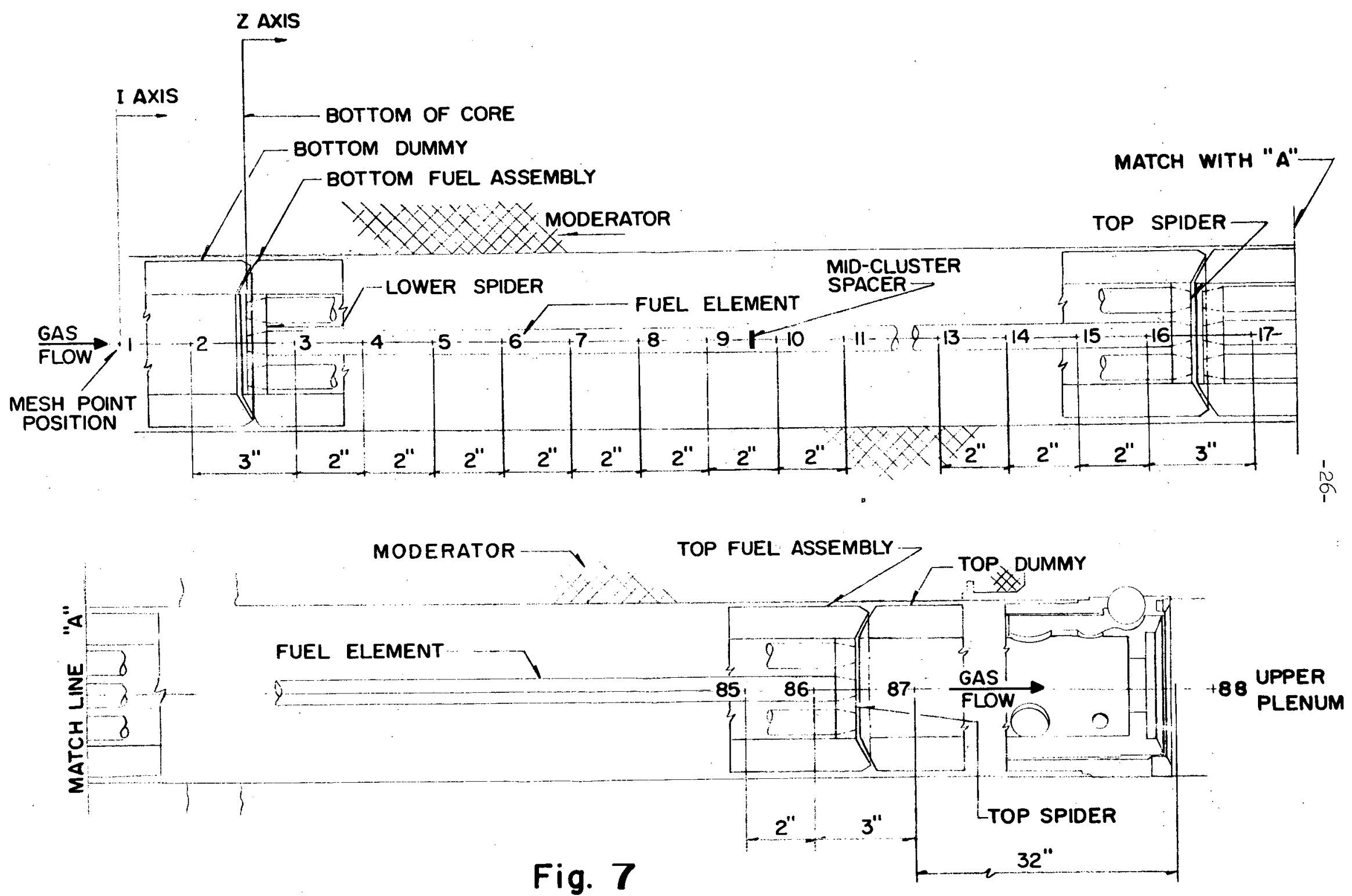

MESH POINT SPACING 
Table 3

AXIAI POSITION OF MESH PUINIS

Mesh

Point

1

2

3

5

7
8

9

10

11

12

13

14

15

16

17

18

19

20

21

22

23

24

25

20

27

28

29

30

31

32

33

34

35

37
38

39

40

41

42

43
44
Increment

Length (Inches)

2

3

2

2

2

2

2

2

2

2

2

2

2

2

2

3

2

2

2

2

2

2

2

2

2

2

2

2

2

3

2

2

2

2

2

2

2

2

2

2

2

2

2
Dist. From

Bottom of

Core (Inches)

$-3.5$

$-1.5$

1.5

3.5

5.5

7.5

$9 \cdot 5$

11.5

13.5

15.5

17.5

19.5

21.5

23.5

25.5

27.5

30.5

32.5

34.5

36.5

38.5

40.5

42.5

44.5

46.5

48.5

50.5

52.5

54.5

56.5

59.5

61.5

63.5

65.5

67.5

69.5

71.5

73.5

75.5

77.5

79.5

81.5

83.5

35.5 
Table 3 (continued)

Mesh

Point

45

46

47

48

49

50

51

52

53

54

55

57

58

59

61

62

63

64

65

66

67

69

70

71

72

73
74

75

76

77

80

81

82

83

84

85
86
Increment

Length (Inches)

2

2

2

2

2

2

2

2

2

2

2

2

2

3

2

2

2

2

2

2

2

2

2

2

2

2

2

3

2

2

2

2

2

2

2

2

2

2

2

3
Dist. From

Botton of

Core (Inches)

88.5

90.5

92.5

94.5

96.5

98.5

100.5

102.5

104.5

106.5

108.5

110.5

112.5

212.5

117.5

119.5

121.5

123.5

125.5

127.5

129.5

131.5

233.5

135.5

137.5

139.5

141.5

143.5

146.5

148.5

150.5

152.5

154.5

156.5

158.5

160.5

162.5

164.5

166.5

168.5

170.5

172.5

175.5 
valid to assume that the temperature of the gas entering the unit cell will not change as it flows through the bottom dummy, and will always be known.

This gas temperature is used as the gas temperature in both the annulus and the fuel streams for the first axial increment. The surface temperatures and the change in gas temperatures are then determined by solving equations 2 through 7 , simultaneously. The gas temperature leaving the increment is obtained by addition of the gas stream temperature rise to the entering gas temperature, and this becomes the inlet temperature for the second increment. The entire procedure is then repeated for each increment until the exit temperature of the gas is known and hence the temperature distribution of the entire unit cell is known.

Since certain assumptions had to be made in obtaining the film coefficient at both surfaces of the sleeve and at the block, a subprogram determines these coefficients so that the method of calculation may be changed with a minimum of effort. Furthermore, these coefficients can be adjusted by input to the program--that is, at the beginning, each calculated film coefficient at each chosen mesh point is multiplied by 1.0 , and this 1.0 is input to the program which can be changed, if desired. The primary objective of this feature is to make possible a study of the effect of uncertainties in the film coefficient.

The pressure distribution is calculated by starting at the top plenum and advancing upstream to the bottom dummy, as pointed out previously; however, the pressure is a function of temperature, friction, 
and loss coefficients, and since the temperature distribution is, in turn, a function of friction factor and the loss coefficients, certain parts of equation 15 are calculated and stored during the process of obtaining the temperature distribution. This stored information is then used in obtaining the pressure distribution. This point is brought out because this information is printed out as $p \Delta p$ and, under certain assumptions which will be brought out below, this $p \Delta p$ is the absolute pressure at mesh point i multiplied by the difference in pressure at mesh point $i+1$ and at mesh point $i$. In equation 15 let

$$
B=\frac{\left[A_{F} /(W F)\right]^{2} g_{c}}{\left(R_{0} / M\right)}
$$

Then

$$
\begin{gathered}
\bar{p}\left(p_{2}-p_{1}\right)=\frac{\bar{T}}{B} \ln \frac{p_{2}}{\mathrm{p}_{1}}-\frac{\bar{T}}{B}\left\{\ln \frac{T_{2}}{T_{1}}+\frac{4 f\left(z_{2}-z_{1}\right)}{2 D_{e}}+\right. \\
\left.\frac{1}{2} \int_{z_{1}}^{z_{2}} \delta\left(z-z_{j}\right) e_{v} d z\right\}
\end{gathered}
$$

Since $P_{2}$ is not greatly different from $P_{1}$, the first term on the right side of equation 16 is small relative to the second term, and equation 16 becomes

$$
\begin{gathered}
\bar{p}\left(p_{2}-p_{1}\right)=-\frac{\bar{T}}{2 B}\left\{2 \ln \frac{T_{2}}{T_{1}}+\frac{4 f\left(z_{2}-z_{1}\right)}{D_{e}}+\int_{z_{1}}^{z_{2}} \delta\left(z-z_{j}\right) e_{v} d z\right\} \\
\bar{p}=\frac{p_{2}+p_{1}}{2} ; \bar{p}\left(p_{2}-p_{1}\right)=\frac{1}{2}\left(p_{2}{ }^{2}-p_{1}{ }^{2}\right),
\end{gathered}
$$


but

$$
p_{2}=p_{1}+\Delta p
$$

then

$$
\begin{aligned}
& \mathrm{p}_{2}^{2}-\mathrm{p}_{1}^{2}=\mathrm{p}_{1}^{2}+2(\Delta \mathrm{p}) \mathrm{p}_{1}+(\Delta \mathrm{p})^{2}-\mathrm{p}_{1}^{2} \\
& \mathrm{p}_{2}^{2}-\mathrm{p}_{1}^{2}=2(\Delta \mathrm{p}) \mathrm{p}_{1}+(\Delta \mathrm{p})^{2}
\end{aligned}
$$

now

$$
(\Delta p)^{2} \ll 2(\Delta p) p_{1}
$$

Therefore

$$
p_{2}^{2}-p_{1}^{2} \approx 2(\Delta p) p_{1}
$$

and equation 17 becomes

$$
p_{1} \Delta p=-\frac{\bar{T}}{\overline{2} \bar{B}}\left\{2 \ln \frac{T_{2}}{T_{1}}+\frac{4 f\left(z_{2}-z_{1}\right)}{D_{e}}+\int_{z_{1}}^{z_{2}} \delta\left(z-z_{j}\right) e_{v} d z\right\}
$$

Equation 18 is solved simultaneously with the equations yielding the temperature distribution, and the results obtained are printed out under the heading of $\mathrm{p} \Delta \mathrm{p}$; however, the pressure distribution which is printed out is an iterative solution of equation 15.

VI. Summary

The above equations and procedures are programmed in Fortran for the IBM 7090 computer. The constants in the equations are the values set by the physical characteristics of the EGCR fuel. The entire program is not reproduced here; however, complete card decks are 
available upon request. Appendix $A$ is the flow sheet for the program with a brief explanation of the input statements and the printouts. Appendix B presents some typical results. Figures B2a through B4b are plotted by a CALCOMP plotter working directly from computer output tapes. Appendix $\mathrm{C}$ is a brief explanation of the treatment given radiation. 
REFERENCES

1. Bird, Stewart, Lightfoot. Transport Phenomena. John Wiley \& Sons, New York - London.

2. Epel, L. G. Radiative Heat Transfer in Multisurfaced Nonblack Enclosures with Application to the EGCR Fuel Bundle. ORNL CF 60-7-71.

3. Flanigan, Lawrence J., et al. Model Studies of Flow and Mixing in the Partially Enriched Gas Cooled Power Reactor. BMI 1397 .

4. Knudsen and Katz. Fluid Dynamics and Heat Transfer. McGraw-Hill Book Company, Inc., New York.

5. Nephew, E. A. Gamma-Ray and Fast Neutron Heat Deposition. ORNL CF $60-10-122$.

6. Oak Ridge National Laboratory. "Gas-Cooled Reactor Project Quarterly Progress Report for Period Ending December 31, 1960." ORNI-3049.

7. Personal communication, G. Samuels and M. E. Lackey to J. C. Robinson (October 1961).

8. Samuels, G. Design and Analys is of the Experimental Gas-Cooled Reactor Fuel Assemblies. Oak Ridge National Laboratory. ORNL-3478.

9. Wilson, M. P., Jr. Thermodynamic and Transport Properties of Helium GA 1355 .

10. United States Atomic Energy Commission, Oak Ridge Operations Office. Experimental Gas-Cooled Reactor Final Hazards Summary Report. ORO-586, Volume I (October 10, 1962). 


\section{APPENDIX A}

\section{PTD-1 FLOW SHEET}

Read first row and column of all input arrays

203

Read remainder of input

DO $10 \quad \mathrm{KIM}=2, \mathrm{~J}$

DO $10 \mathrm{KING}=2, \mathrm{I}$

Set temperature element

$(I, J)$ equal to zero

10

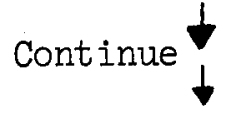

DO . $\quad 151 \quad \mathrm{KIM}=2, \mathrm{~J}$

DO $151 \mathrm{KING}=2$, J

Set coolant temperature

elements $(2,2)$ equal

to $970^{\circ} \mathrm{R}$.

Calculate fuel clad film

coeff. element ( $I, J$ )

\section{Call Films}

Calculate Radiative coefficient elements ( $I, J)$ based on surface temperature elements ( $I, J-I$ )

Calculate surface temperature elements $(I, J)$

Calculate friction factor and loss coefficient

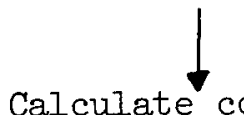

Calculate coolant temperature

elements $(I+I, J)$
Films

Calculate sleeve and block film

coefficient elements $(I, J)$

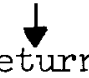




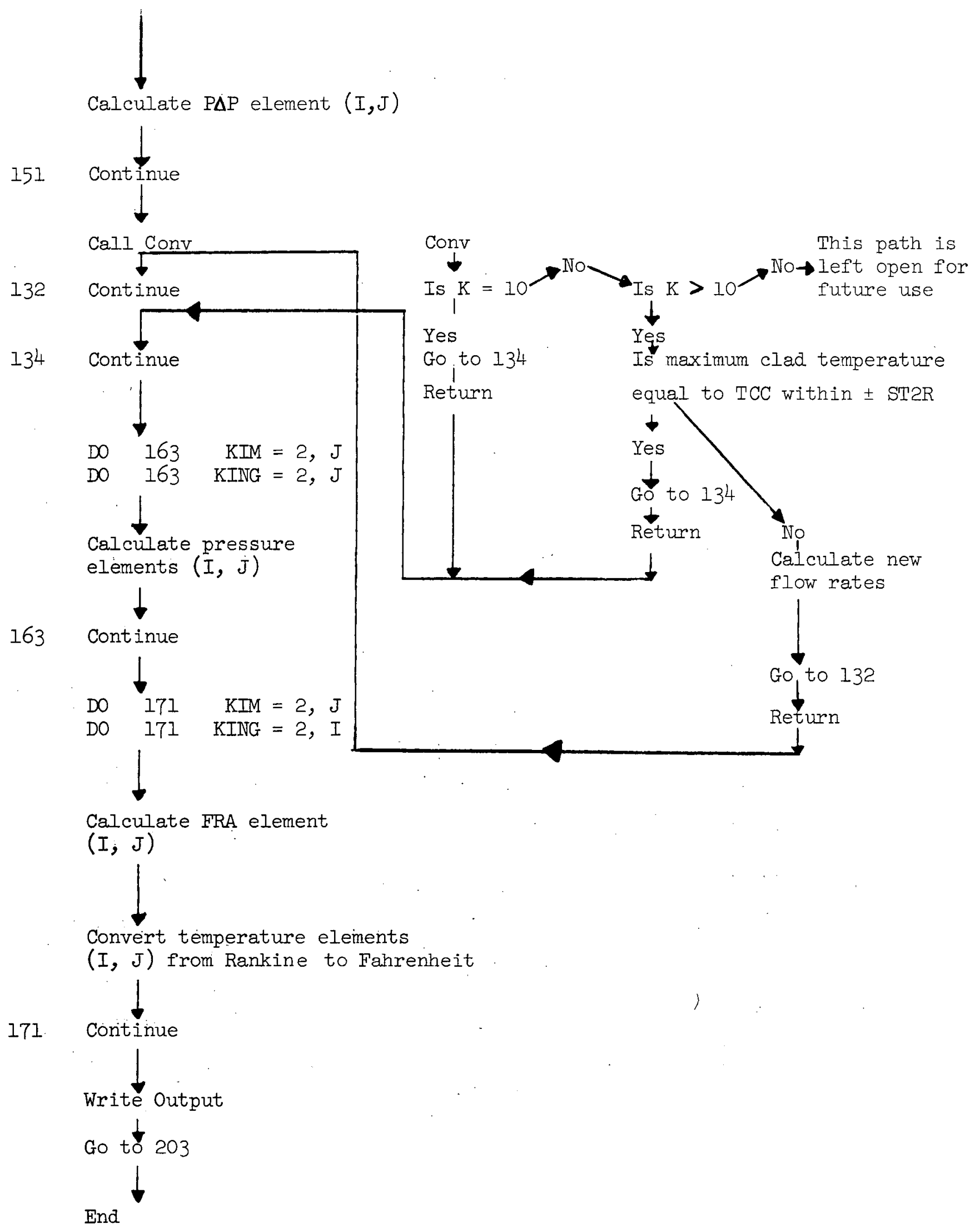




\section{PTD INPUT STATEMEIVTS}

The input statements to the code are:

READ INPUT TAPE 10, 1, I, (CL(M), CS(M), CA(M), CB(M), ZA(M), ZB(M),

$$
\mathrm{M}=1, I)
$$

READ INPUT TAPE 10, 469, I (G(M), M=1,I)

where subscript $M$ (or I) refers to mesh point $I$.

$\mathrm{CL}(I)=$ coefficient used in calculating the clad film coefficient (figure 5).

CS(I) = coefficient used in calculating the sleeve film coefficient (figure 6).

$\mathrm{CA}(I)$ and $\mathrm{CB}(I)$ are inputs at each mesh point which can be used as required.

$\mathrm{ZA}(I)=$ distance (feet) between mesh point $I$ and $I-I$.

$\mathrm{ZB}(I)=$ distance (feet) between mesh point $I+I$ and $I$.

$G(I)=$ relative axial heat generation rate at mesh point $I$.

$I$ is read in as 87 ( 87 mesh points).

READ INPUT TAPE $10,2, \mathrm{I},((\mathrm{TC}(\mathrm{K}, J), \operatorname{TSF}(\mathrm{K}, J), \operatorname{TSA}(\mathrm{K}, J), \operatorname{TB}(\mathrm{K}, J)$, $\mathrm{TF}(K, J), T A(K, J), K=2, I), J=1)$.

This statement reads in the first column of each array for each of the six temperatures for each specific mesh point. TC, TSF, TSA, TB,TF, and TA are the absolute temperatures $\left({ }^{\circ} R\right)$ of the clad, sleeve on fuel side, sleeve on annulus side, block, fuel coolant, and annulus coolant, respectively. Note that if all of these are equal, the results at the output for $\mathrm{J}=2$ are for the analysis neglecting thermal radiation. 
READ INPUT TAPE 10, 2, J, ( (TC(I,L), TSF(I,I), TSA(I,L), TB(I,L), $T F(I, I), T A(I, I), I=I), I=2, J)$.

This statement reads in the first row of each "temperature array;" where $2 \leqq J \leq 9$ due to the starting position for the lower limit and the dimension statement for the upper limit.

READ INPUT TAPE 10, 5, FR, ST2R

where $\mathrm{FR}$ = radial power ratio for a specific channel, and

$\mathrm{ST2R}=$ tolerance on the maximum clad temperature when this program is being used, i.e., $\mathrm{K}$ (given below) = 11 .

READ INPUT TAPE 10, 4, P89

where P89 is the pressure in top plenum in psia.

READ INPUT TAPE .10,6, $\mathrm{K}$

where $K=10$ means that input flow rate is not adjusted, and

$K=I I$ means that flow rate is altered until the maximum clad temperature is TCC ST2R (TCC given below).

READ INPUT TAPE 10, 3, WA

where $W A=$ annulus flow rate $(\mathrm{lb} / \mathrm{hr})$.

READ INPUT TAPE 10, 3, WF

where $W F=$ fuel coolant flow rate $(\mathrm{lb} / \mathrm{hr})$.

READ INPPUT TAPE 10, 6, JIG

where $J I G=$ integer, and this integer determines the frequency at which $\operatorname{DELTA}(I, J)$ and the various temperatures and film coefficients are printed out in the I subscript; i.e., if JIG $=3$, DELTA is printed out for $(2, J),(5, J),(8, J),-\cdots(84, J),(87, J)$, and similarly for the various temperatures and film coefficients, and $\operatorname{DELTA}(I, J)=T C(I, J)-T F(I, J)$. 
READ INPUT TAPE 10, 7, WCC, TCC

where $W C C=$ fraction of total flow going to annulus (used if $K=l l$ ), and

TCC $=$ the desired maximum clad temperature $\left({ }^{\circ} \mathrm{R}\right)$.

READ INPUT TAPE 10, 7, CMOD

where CMOD = thermal conductivity of the graphite sleeve (Btu/hr-ft- $\left.{ }^{\circ} \mathrm{F}\right)$.

READ INPUT TAPE 10, 6, J

where $J=$ number of iterative solutions on thermal radiative effects which are desired: $\quad 2 \leq \mathrm{J} \leq 9$

READ INPUT TAPE 10,760, EYED

where EYED is a number for identification purposes only.

The output information is identified and needs little explanation. As pointed out previously, the various temperatures and film coefficients are printed out in each column in steps of JIG, but the row selected starts at $\mathrm{J}=2$ and progresses in steps of two. The output is in column form, i.e., under the heading of $\mathrm{TC}(I, J)$. The output is (reading down) from $\mathrm{TC}(I, 2)$ to $\mathrm{TC}(87,2)$, the next number is $\mathrm{TC}(1,4)$, and so on, to $\mathrm{TC}(87,4)$. This is repeated until the value of $J$ is reached or a value within one unit of $J$ (depending on whether $J$ is even or odd). The film coefficients are printed out in the same fashion except that the first number read out of a column is for $I=2$. The axial position in the reactor for a specific mesh point is given in table 3. $R C$ and $R S$ are the thermal radiative coefficients for the clad to sleeve and sleeve to block, respectively, in $\mathrm{Btu} / \mathrm{hr}-\mathrm{ft}^{2}-{ }^{\circ} \mathrm{F}$.

Pressure distribution, $p \Delta p$, and FRA are printed out in the same fashion as the film coefficients, except that JIG is always unity. FRA is the ratio of the heat removed from the surface of the sleeve to the annulus coolant to the heat generated in the sleeve at a specific mesh point. 
The Reynolds number in the annulus is printed out, starting at mesh point $I=2$ and progressing in steps of seven. Also, it starts at $J=2$ and progresses in steps of two. It is read from left to right for a fixed $J$ until $I$ is exhausted, and then $J$ is advanced by two and the procedure repeated.

The DEITA $(I, J)$, as pointed out previously, starts at $I=2$ and progresses in steps of JIG from left to right; however, the first run is for $J=2$, and the last is for $J=J$ (no intermediate printouts in $J$ ). 


\section{APPENDIX B}

\section{RESULTS FROM PTD-1}

The results obtained from the PTD-I program are presented in this section for (I) an output coolant temperature of $1075 \mathrm{~F}$ for a given radial power ratio (local-to-average), and (2) the flow rates for a maximum clad temperature of $1800 \pm 20 \mathrm{~F}$ for various radial power ratios. The axial power distribution used is that presented in figure 3 for both cases. Cases 1 and 2 are with and without thermal radiation.

The results for case 2 are given in figure $B-1$, where flow rate is plotted against the radial power ratio for a maximum clad temperature of $1800 \pm 20 . \mathrm{F}$ for an analysis with and without thermal radiation.

For case 1 , a power ratio of 1.35 (local-radial to averageradial) is chosen. An annulus flow rate of $134.31 \mathrm{bm} / \mathrm{hr}$ and a fuel coolant flow rate of $2281.8 \mathrm{lbm} / \mathrm{hr}$ are used. The axial temperature distributions for the clad, fuel coolant, and sleeve on fuel side are presented in figure B-2 (with and without thermal radiation). Figure B-3 is the same information for the sleeve on annulus side, annulus coolant, and the block surface. Figure $\mathrm{B}-4$ is the pressure distribution in the fuel coolant stream. 


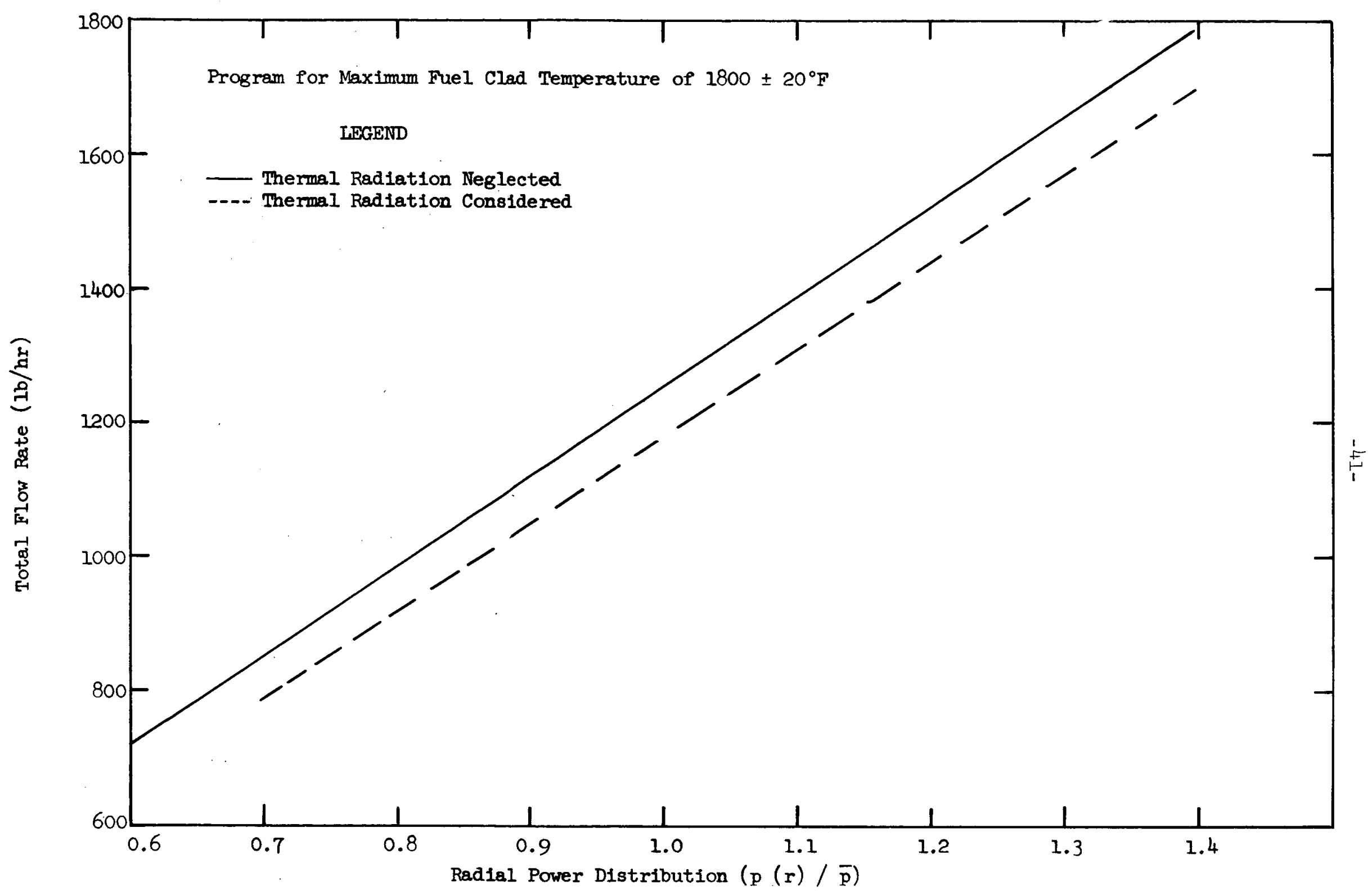

Figure B-1. FLOW VERSUS RADIAL POWER DISTRIBUTION FOR 60-INCH BANK INSERTION 


\section{$-42-$}

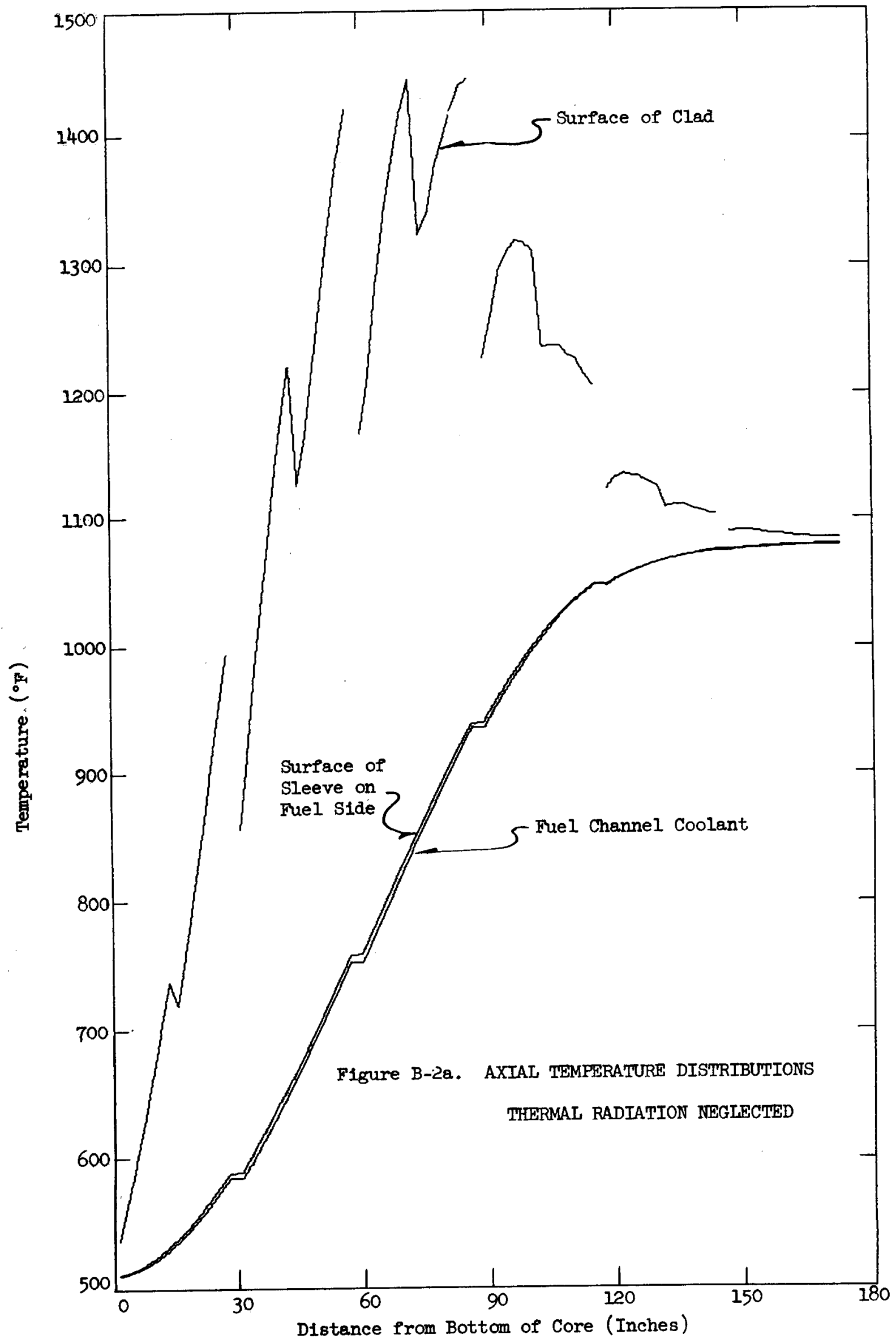


$-43-$

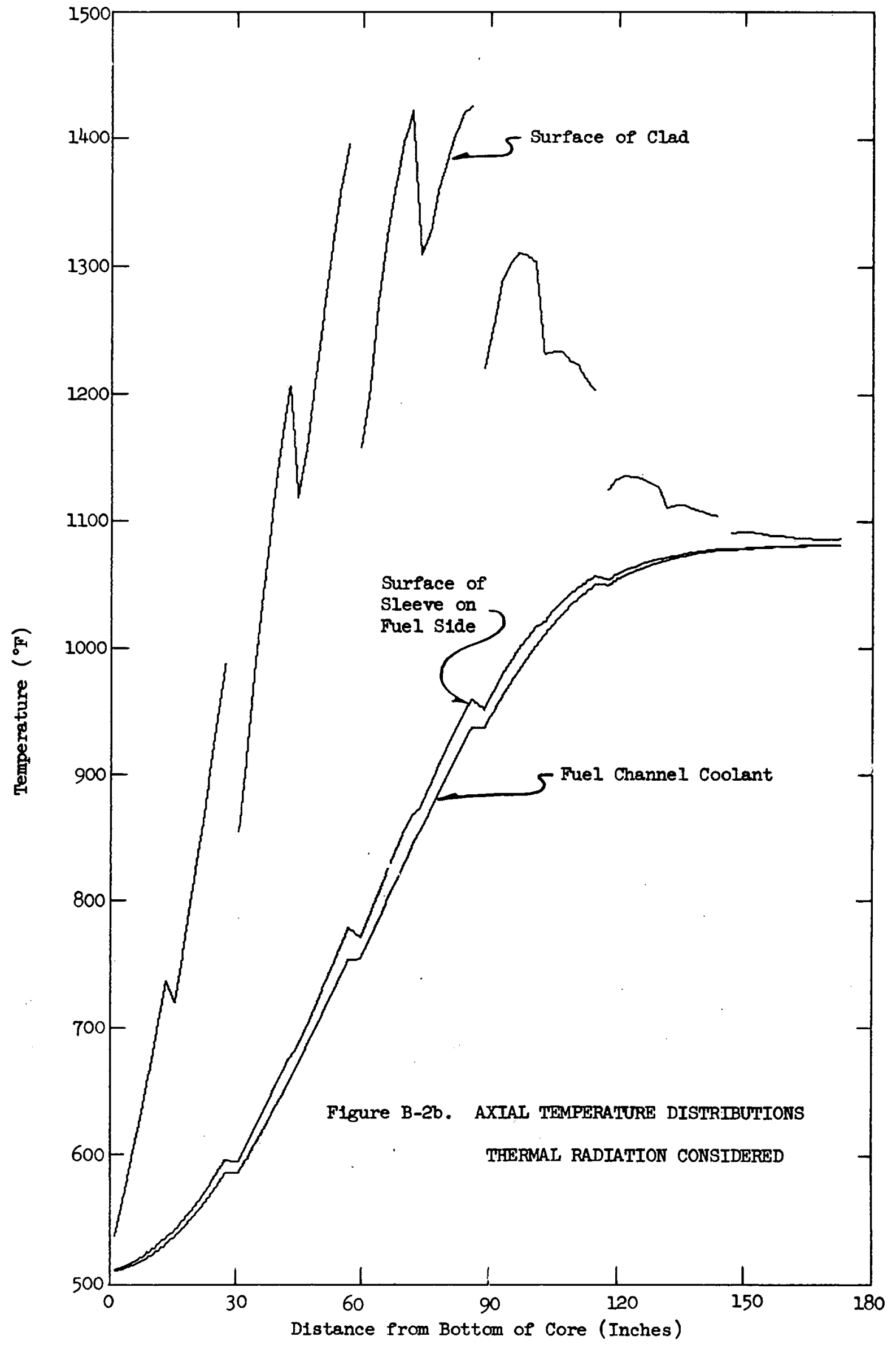


$-44-$

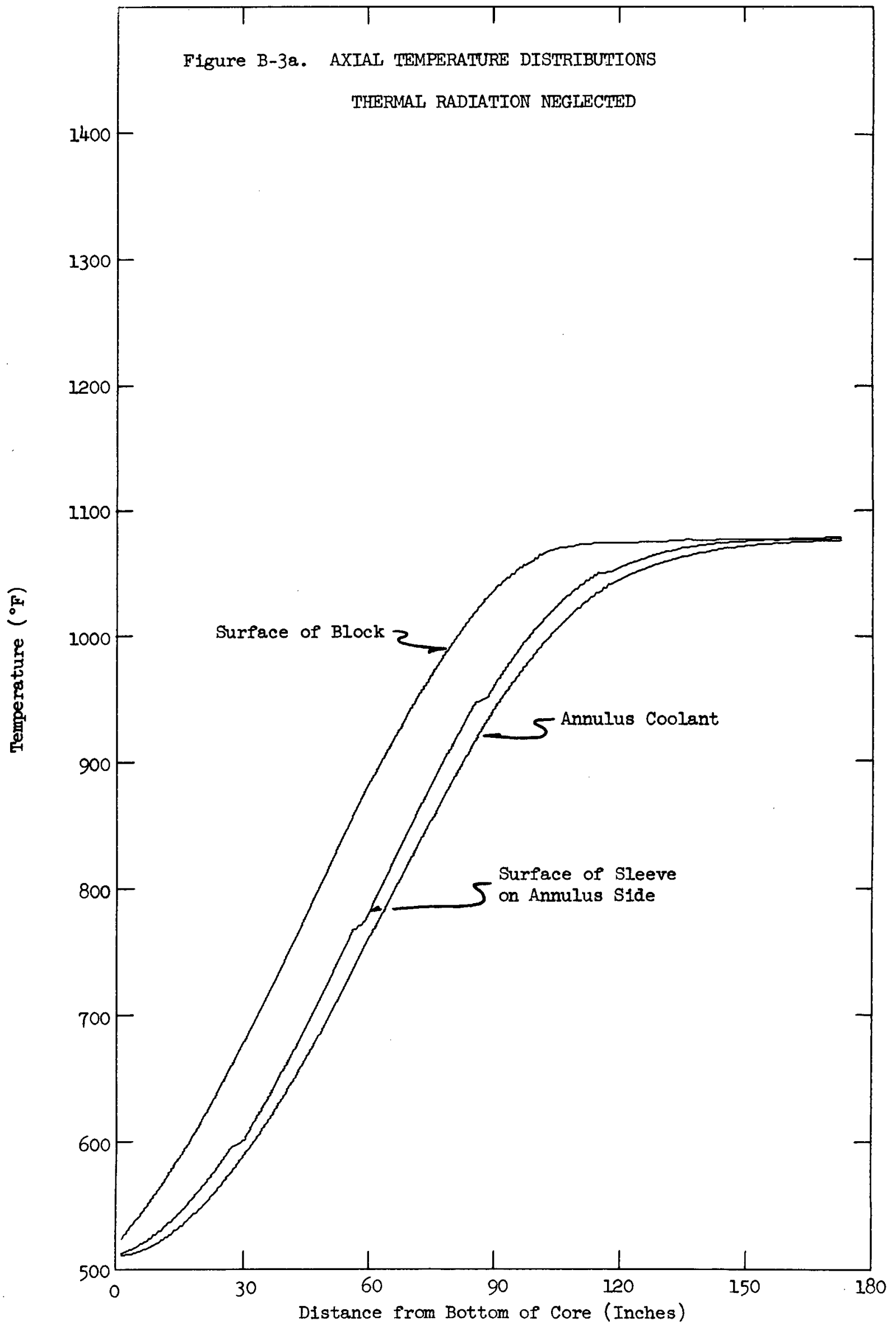


$-45-$

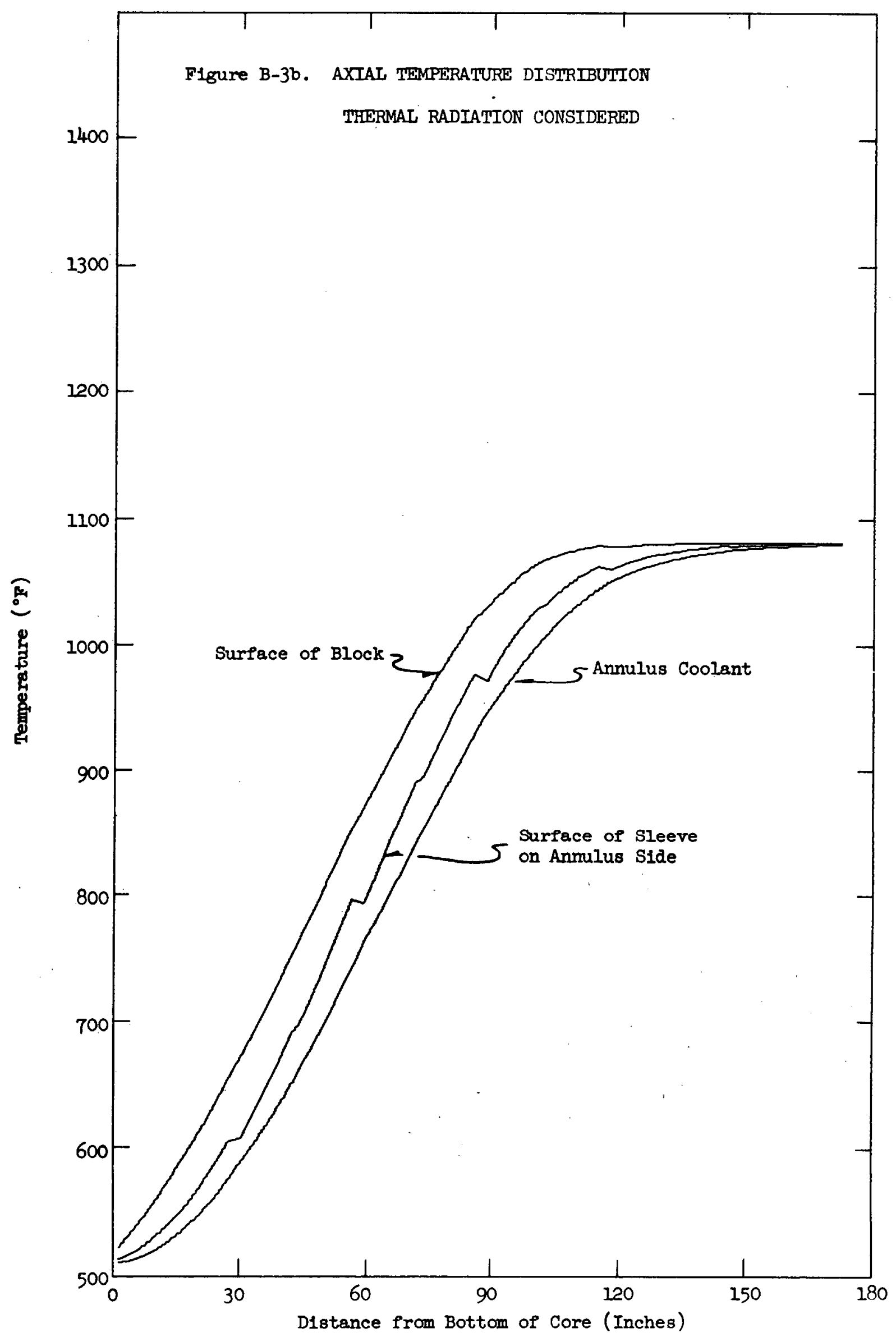


$-46-$

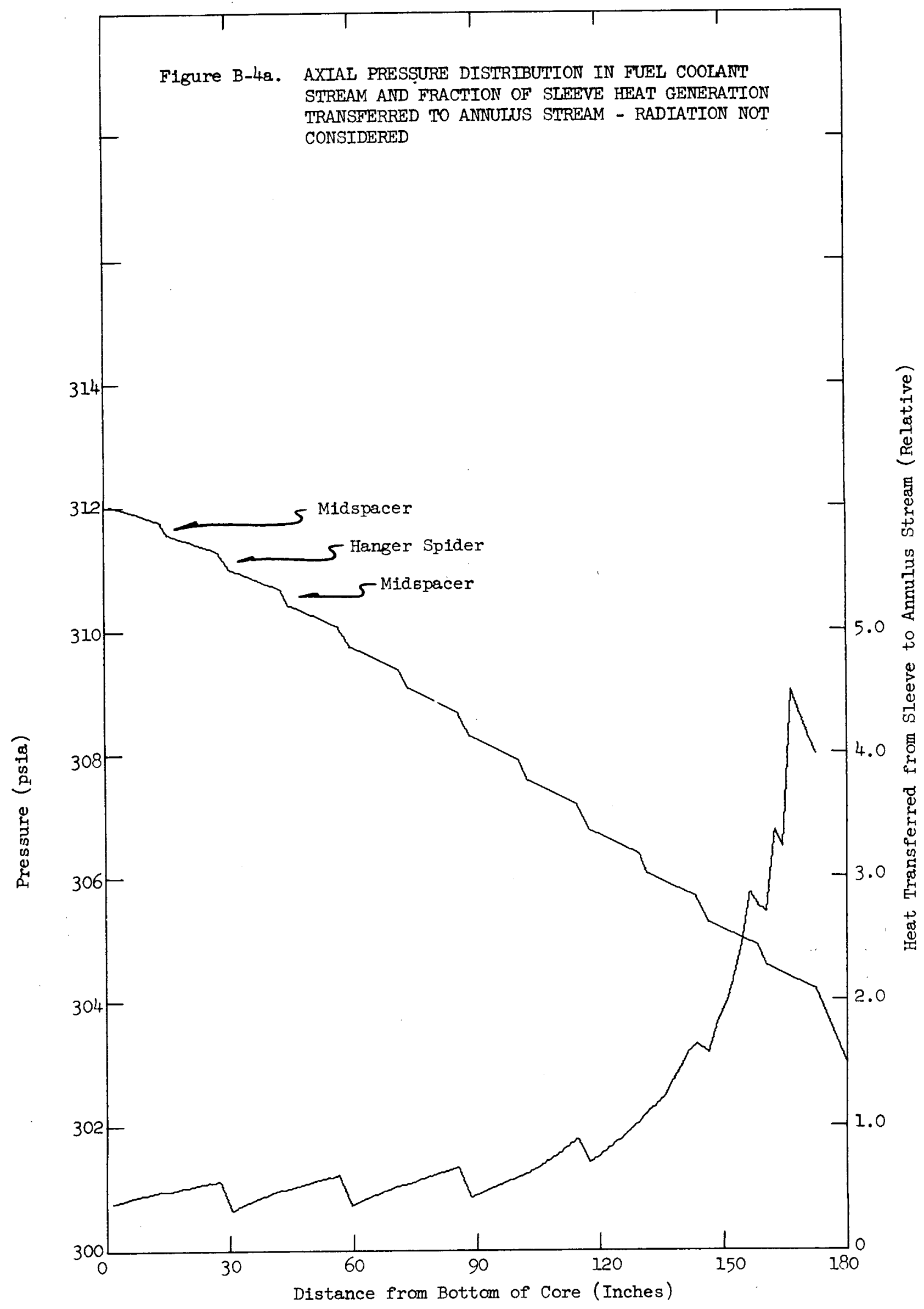




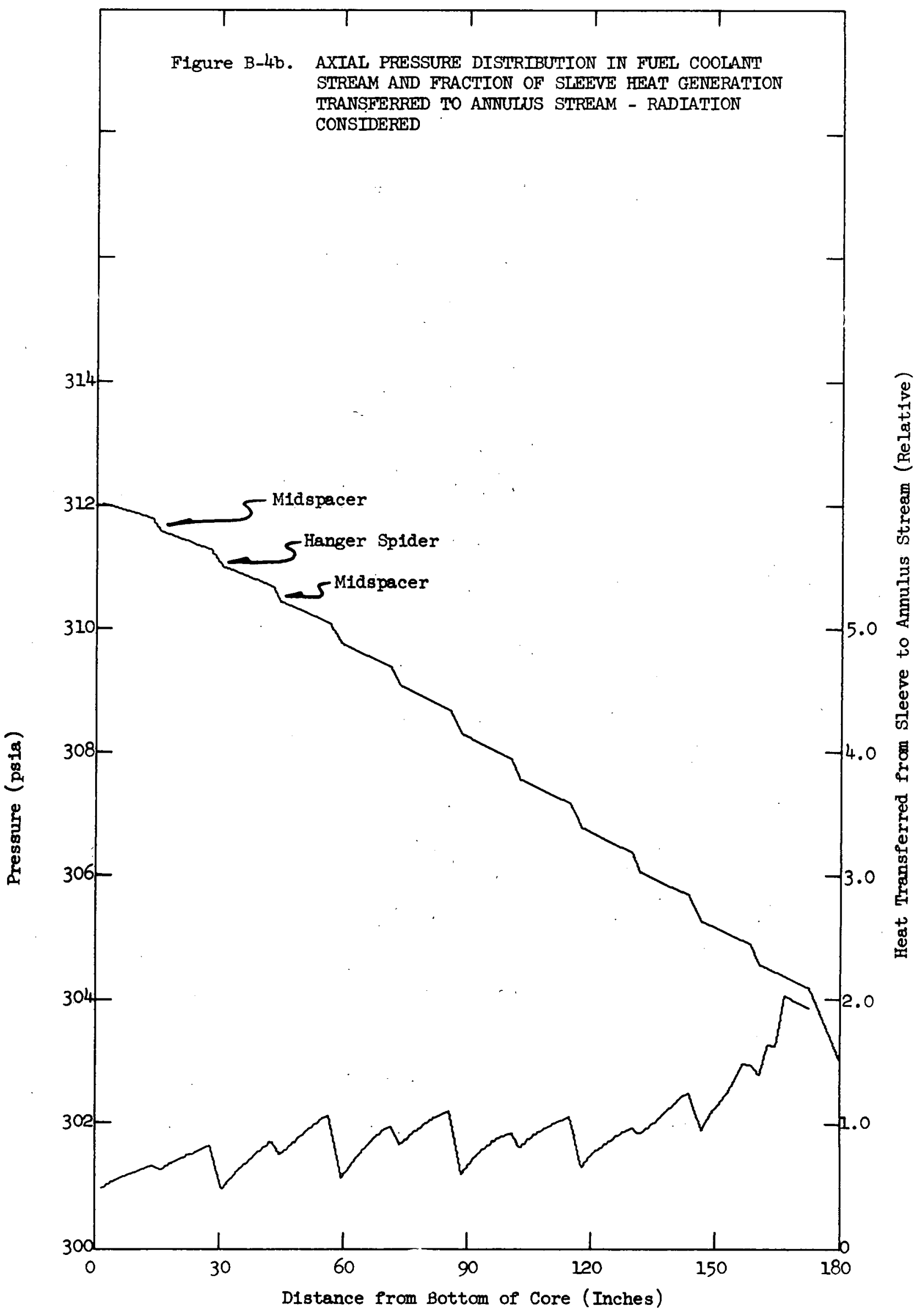




\section{APPENDIX C}

\section{TREATMENT OF THERMAI RADIATION}

Thermal radiation can be included in any unit cell analysis, if desired. The radiative coefficient is calculated at each mesh point from temperatures obtained from a previous calculation; therefore, a starting temperature distribution is read into the program. If all of these input temperatures are equal, then the radiative coefficient is zero for the first axial pass at each space mesh point; hence the results are those desired for an analysis which neglects thermal radiation. The second, third, fourth, etc., passes converge to the results obtained for an analysis which includes thermal radiation. The program is written so as to consider seven iterations for thermal radiation. The number seven is arbitrarily selected, but, judging from cases which have been checked, this is a sufficient number of iterations for convergence. The number of iterations is limited (due to storage space) because the results of each are stored, and every other iteration is printed out. The various temperatures, temperature dependent coefficients, etc., can be thought of as elements of two-dimensional arrays where the elements in the columns represent the space mesh points. The elements reading out a row represent the results obtained, based on a thermal radiative coefficient, which in turn is based on previous results (in the same row). The following example helps to clarify these statements. Consider the clad surface temperature with subscript $(I, J)$. Then

TC $(2,5)=$ clad temperature at mesh point 2 after the fourth iteration. 
TC $(80,2)=$ clad temperature at mesh point 80 after the first iteration.

Note: If $\operatorname{TC}(I, I)-\operatorname{TSF}(I, I)$ and $\operatorname{TSA}(I, I)=\operatorname{TB}(I, I)$,

then $T C(I, 2)$ and all other parameters at $J=2$ for all $I$ are the results of the "no thermal radiation analysis." 
0

$\neq$

$-$ 